\title{
Bronchoscopic lung volume reduction
}

\author{
M.I. Polkey and N.S. Hopkinson
}

\begin{abstract}
Surgical lung volume reduction can improve exercise performance and forced expiratory volume in one second in patients with emphysema. However, the procedure is associated with a $5 \%$ mortality rate and a nonresponse rate of $\sim 25 \%$. Accordingly, interest has focused on alternative ways of reducing lung volume. Two principle approaches are used: collapse of the diseased area using blockers placed endobronchially and the creation of extrapulmonary pathways. Preliminary data from the former approach suggest that it can be successful and that the magnitude of success is related to reduction in dynamic hyperinflation.
\end{abstract}

\section{KEYWORDS: Bronchoscopic lung volume reduction, emphysema}

$\mathbf{T}$ he reintroduction in the mid-1990s of the surgical method originally conceived by BRANTIGAN et al. [1], lung volume reduction, showed that under certain circumstances this treatment could improve the forced expiratory volume in one second (FEV1), indices of resting hyperinflation and quality of life [2].

However, three factors taken together have meant that lung volume reduction surgery (LVRS) has been useful in only a minority of patients. A significant proportion of patients, between one-quarter and one-third, fail to derive significant benefit from the procedure. This in itself might not matter if it were not for the second problem, which is that in large series, the mortality rate has been $\geqslant 4-5 \%[2-4]$. While this risk might be acceptable if success were guaranteed, it is less appealing if it is not. Finally, in order to reduce mortality and morbidity, most groups impose safety criteria so that patients who are too disabled are not eligible for LVRS. Thus, in the present authors' centre, for example, patients must have a transfer factor of the lung for carbon monoxide $(\mathrm{TL}, \mathrm{CO})>30 \%$ predicted and a shuttle walk distance $>150 \mathrm{~m}$. The effect of this was an acceptance rate for LVRS in the study by GEDDES et al. [3] of just $28 \%$; this figure is especially sobering if one recalls that in UK practice, the pool of patients assessed was largely drawn from patients who had already been screened and thought to be potentially suitable by chest physicians in hospital practice.

These factors suggest a need for a treatment that is either more likely to be effective or, alternatively, less dangerous and/or reversible. Two principle approaches have been described as follows. 1) An endobronchial blocker or valve is positioned with the aim of achieving distal collapse. 2) An extrapulmonary pathway is created, which allows increased expiratory flow from the lung. The latter concept was originally proposed in 1978 by MACKLEM [5] but has not so far been tested in vivo; thus, the possible effects on dynamic or resting hyperinflation remain unknown. Data from explanted lungs suggest that the approach could be successful if the technical problems could be overcome [6].

There is more information in the public domain regarding the first of the two listed approaches. SABANATHAN et al. [7] suggested endobronchial blockade as an alternative approach. Sadly, S. Sabanathan, who appreciated these issues, died whilst developing the concept; however, preliminary data from procedures performed between November 1996 and April 1997 were published posthumously and showed that significant improvement was possible using this approach. However, the blockers initially used were not designed for endobronchial occlusion and later patients in the series had devices inserted that were custom built in the hospital in which S. Sabanathan practiced (Bradford Royal Infirmary, Bradford, UK). Significant problems were observed with migration of the first type of blockers and, in the case of the custom-built devices, one episode of blocker disintegration occurred. No estimate of dynamic hyperinflation $(\mathrm{DH})$ was reported in this series and static lung volumes were measured using helium dilution techniques alone.

Biotechnology companies have now taken up the challenge and two devices are commercially available. The Emphasys system (Emphasys Medical, Inc., Redwood City, CA, USA) uses a one-way duckbill valve, which is inserted in such a way that air is permitted to leave the subtended segment but not enter it. The valve is secured and supported by a collapsible metal framework. The initial valves
AFFILIATIONS

Respiratory Muscle Laboratory, Royal Brompton Hospital and National Heart and Lung Institute, London, UK.

\section{CORRESPONDENCE}

M.I. Polkey

Respiratory Muscle Laboratory

Royal Brompton Hospital and

National Heart and Lung Institute

Fulham Road

London SW3 6NP

UK

Fax: 442073518939

E-mail: m.polkey@

rbh.nthames.nhs.uk

\section{SUPPORT STATEMENT}

The research programme in endobronchial lung volume reduction was partially supported between 2001 and 2006 by an unrestricted educational grant from Emphasys Medical, Inc. (Redwood City, CA, USA). Neither M.I. Polkey nor N.S Hopkinson has received personal payment at any time from Emphasys. This article has not been seen by Emphasys prior to submission. 
(fig. 1a) were inserted over a guidewire, but later models (fig. 1b) can be inserted through the working channel of a fibreoptic bronchoscope. Five human studies have been reported with the valve [8-12] The Spiration (Spiration, Inc., Redmond, WA, USA) device is an umbrella-shaped instrument, arranged so that the convex surface is positioned distally, with the aim, again, of allowing expiratory but not inspiratory flow (fig. 2); to the best of the present authors' knowledge, no human data has as yet been reported from this device.

\section{DATA CONCERNING HYPERINFLATION AND ENDOBRONCHIAL LUNG VOLUME REDUCTION}

One problem when assessing the effect of an intervention on $\mathrm{DH}$ is that direct measurement of $\mathrm{DH}$ requires time and expertise; it is therefore often omitted. Nevertheless, a relationship exists between measures of resting hyperinflation and $\mathrm{DH}$; of these, the best predictor is inspiratory capacity (IC; total lung capacity (TLC) minus end-expiratory lung volume (EELV)) [13]. In static measurements, therefore, improvement in plethysmographic lung volume is likely to indicate an

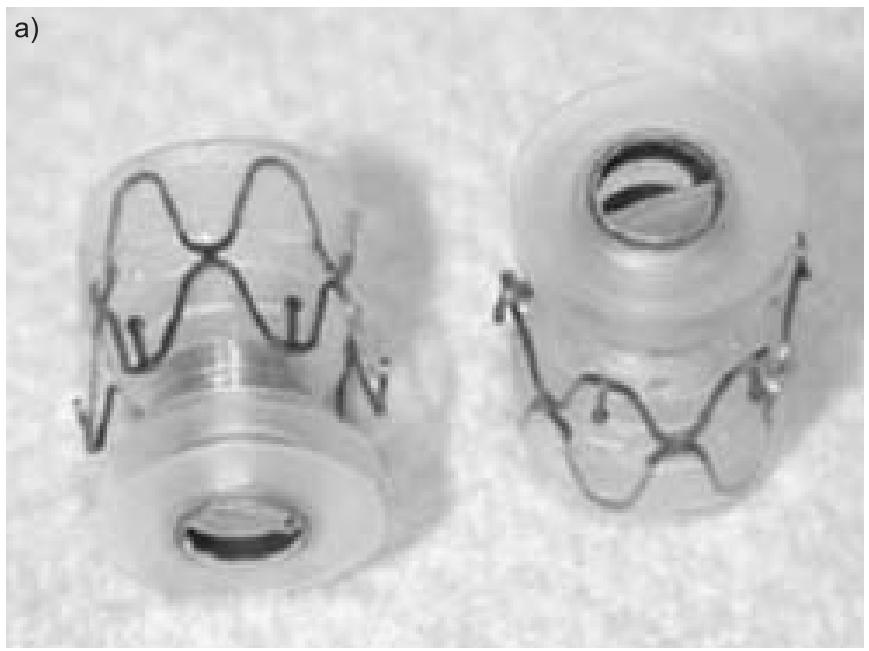

b)

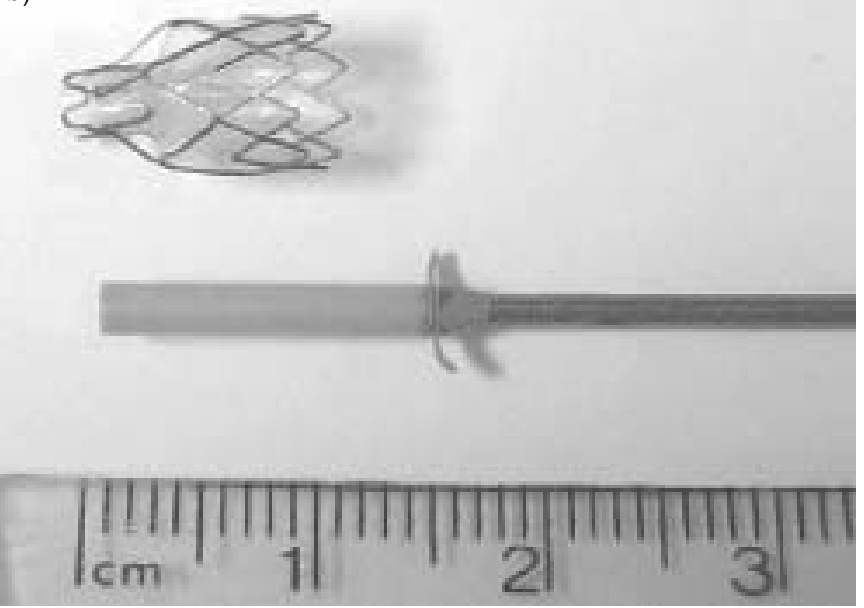

FIGURE 1. Emphasys (Emphasys Medical, Inc., Redwood City, CA, USA) endobronchial valves. a) Initial Emphasys endobronchial valve; b) modified Emphasys endobronchial valve, suitable for transcopic insertion. improvement in $\mathrm{DH}$, even where this has not been specifically measured.

\section{EXPERIENCE WITH ENDOBRONCHIAL THERAPY}

TOMA et al. [12] were the first to report on the use of the Emphasys valve for bronchoscopic lung volume reduction (BLVR). Data from eight patients were presented. Despite the small sample size, a statistically significant improvement in FEV1 was observed, with an increase from 0.79 L (range 0.611.07 ) to $1.06 \mathrm{~L}(0.75-1.22$; difference $34 \%, \mathrm{p}=0.028)$. DH was not measured but a nonsignificant improvement in indices of resting hyperinflation as judged by whole body plethysmography was noted.

SNELL et al. [8] completed their study before the present authors, and it was also published in 2003. SNELL et al. [8] used an earlier version of the valve illustrated in figure $1 \mathrm{a}$ and aimed to achieve bilateral lung volume reduction, whereas the present authors aimed to achieve unilateral treatment. No improvement was observed in any parameter except $T \mathrm{~L}, \mathrm{CO}$, although SNELL et al. [8] also found valve insertion to be safe and well tolerated. $\mathrm{DH}$ was not measured but since no change was

a)
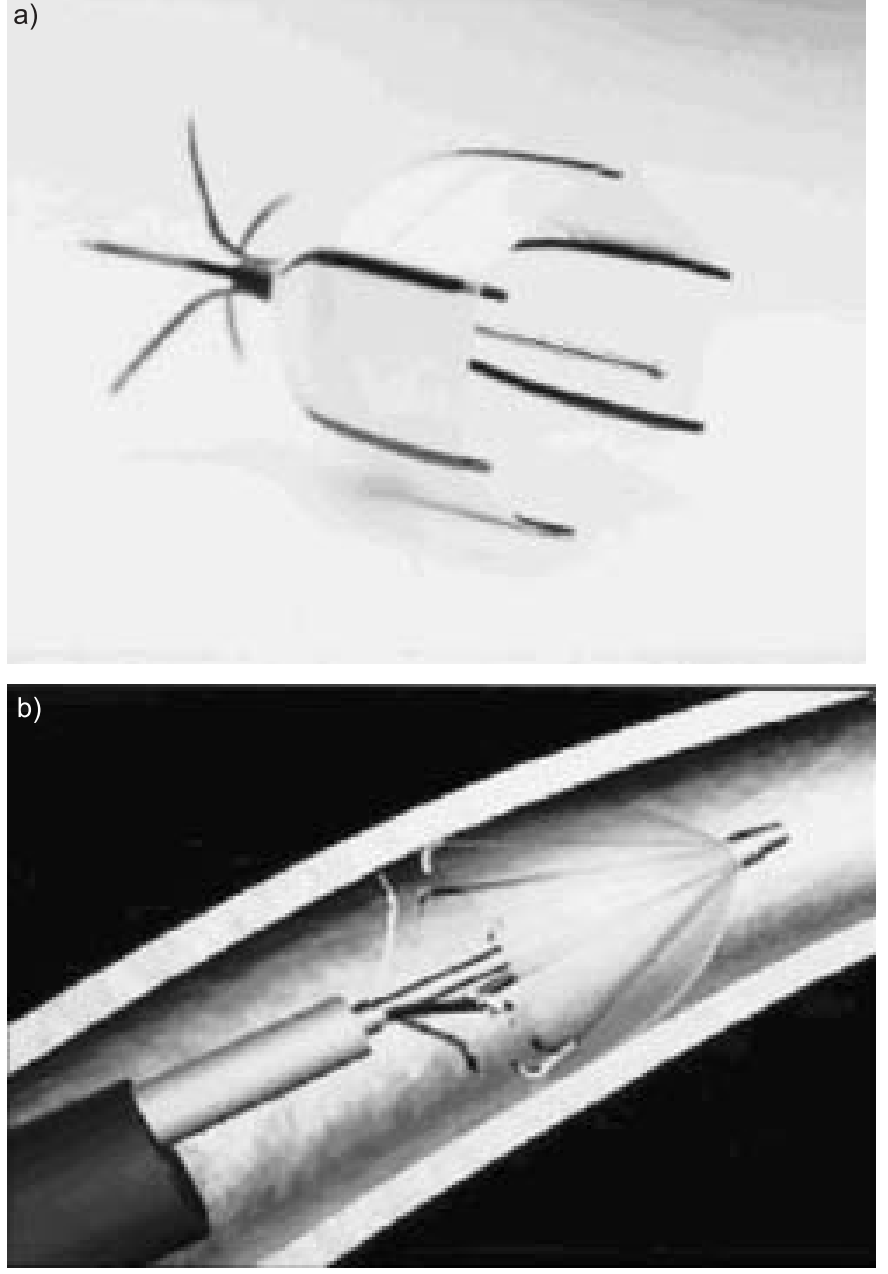

FIGURE 2. a) The Spiration (Spiration, Inc., Redmond, WA, USA) device. b) The device is arranged so that the convex surface is positioned distally, with the aim of allowing expiratory but not inspiratory flow. 

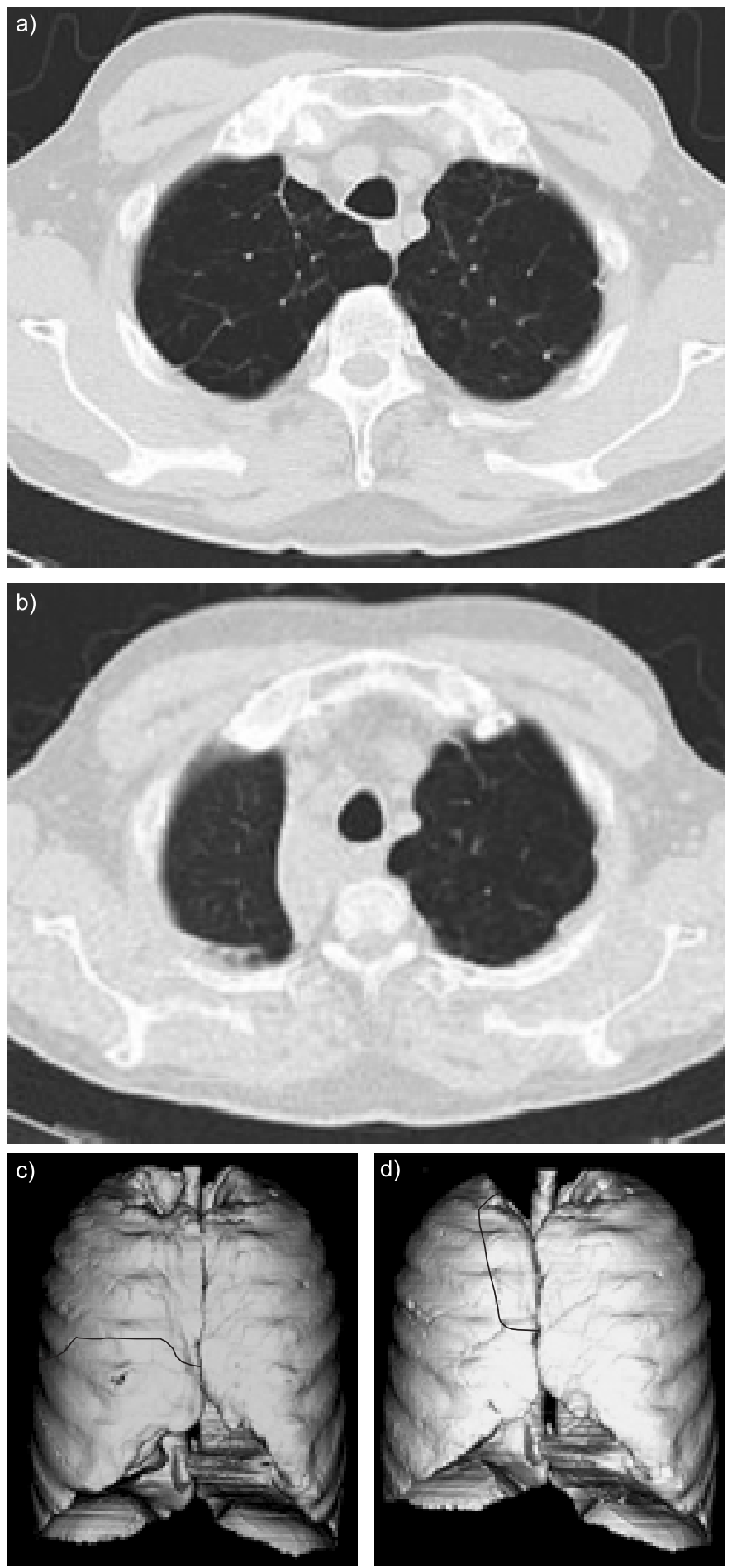

FIGURE 3. Computed tomography before ( $a$ and c) and after ( $b$ and $d$ ) placement of endobronchial valves to the right upper lobe. Post-procedure atelectasis is shown with movement of the fissure (- on the coronal reconstruction). Image courtesy of T. Toma and D.A. Hansell (both at the Dept of Medicine and Radiology, Royal Brompton Hospital, London, UK).

observed in static lung volumes it seems unlikely that significant improvement in DH occurred.

YIM et al. [9] reported 20 patients who had undergone either unilateral $(n=12)$ or bilateral valve insertion, mostly but not exclusively in their upper lobes. There was a significant improvement in FEV1 from 0.73 to $0.92 \mathrm{~L}$ at 3 months $(p=0.009)$, but trends towards improvement in gas transfer and plethysmographic lung volumes failed to achieve statistical significance. DH was not measured in the study by YIM et al. [9].

VENUTA et al. [10] studied 13 patients undergoing unilateral or $(n=2)$ bilateral BLVR, mostly but not exclusively in the upper lobes. There was a significant improvement in FEV1 from 0.75 to $1.00 \mathrm{~L}$ at 3 months $(\mathrm{p}=0.01)$. In addition, significant falls were observed in plethysmographic lung volumes and mean $\mathrm{TL}, \mathrm{CO}$ rose from $33 \%$ pred to $50 \%$ pred. Again, DH was not measured in this study.

The present authors recently reported the only study of BLVR in which DH was directly measured [11]. The study observed 19 patients who were treated with unilateral endobronchial valve insertion; key measurements were made for 4 weeks following the procedure. As in previous studies, a statistically significant improvement in mean FEV1 (28 to $31 \%$ pred, $\mathrm{p}<0.05)$ and in mean $T \mathrm{~L}, \mathrm{CO}(36$ to $41 \%$ pred, $\mathrm{p}=0.016)$ was observed. A statistically significant improvement in TLC and FRC was observed, though this failed to reach significance in the case of residual volume. Although lobar atelectasis occurred in some cases (fig. 3), it was in a minority of subjects.

DH was assessed during a constant rate cycle endurance test performed at $80 \%$ of maximal work rate, as determined by a pre-procedure incremental test. The IC method was used, which assumes that TLC is fixed; briefly, IC manoeuvres were performed every minute to assess changes in EELV. Both peak and isotime values were compared, isotime being defined as the final 30-s period achieved on the shorter of the two tests. In a previous study [11], the present authors observed a mean reduction in EELV from $7.60 \pm 1.6$ to $7.18 \pm 1.7 \mathrm{~L}(\mathrm{p}=0.03)$ and at isotime from $7.47 \pm 1.5$ to $6.97 \pm 1.7 \mathrm{~L}(\mathrm{p}=0.05)$. However, examination of the individual data (fig. 4) shows that there was variation in the change in IC observed. Changes in IC showed a strong correlation with indices of neuromechanical coupling (fig. 5).

A priori, the present authors divided patients into improvers and nonimprovers. Improvers were defined as patients who were able to show an increase of both $60 \mathrm{~s}$ and $30 \%$ in endurance time on the constant rate cycle endurance test. Nine out of 19 patients $(47 \%)$ met this criterion. In stepwise regression analysis, only change in resting IC and $\Delta T \mathrm{~L}, \mathrm{CO}$ were retained as independent predictors, producing an equation that explained $81 \%$ of the variation in endurance time $(\mathrm{p}<0.0001)$. If patients with atelectasis were excluded, again only the same two variables were retained in the model $\left(\mathrm{r}^{2}=0.61 ; \mathrm{p}=0.002\right)$. Taken together, the present authors believe that these data confer the following messages. 1) Endobronchial lung volume reduction works in some patients and is at least as safe as surgical LVRS, probably safer. 2) Atelectasis after the procedure increases the likelihood of a successful outcome, but its absence does not preclude one. 3) The key physiological mechanisms seem to be reduction in $\mathrm{DH}$ and improvement in ventilation/perfusion ratio matching.

As an aside, it is interesting to note that no increase in endurance time was observed in patients who reported 


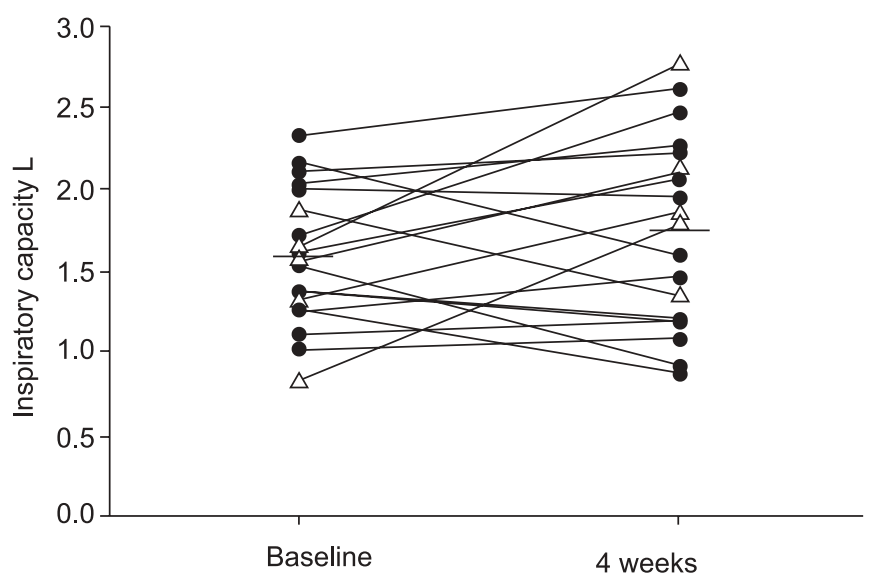

FIGURE 4. Individual data for inspiratory capacity at isotime in patients submitted to unilateral bronchoscopic lung volume reduction. A mean increase is observed (i.e. a fall in end-expiratory lung volume). However, mean improvement includes some patients with reduced dynamic hyperinflation (DH) after the procedure and some with increased $\mathrm{DH} . \Delta$ : patients who developed atelectasis (with the exception of one patient, who developed a pneumothorax, these patients invariably improved); $\bullet$ : patients who did not develop atelectasis. Taken from [14].

exercise limitation due to leg discomfort either alone or with dyspnoea $(n=6)$, whereas a mean increase of $129 \mathrm{~s}$ was observed in patients limited by dyspnoea alone; this may prove to be a useful selection criteria in future trials.

\section{FUTURE DIRECTIONS}

Although FEV1 will continue to be measured in trials of BLVR, it may not, as is the case with pharmacological interventions, be the most sensitive index. It would be worth attempting to detect which patients derive the most benefit from the procedure, although to some extent this would become less important if the pricing strategy of manufacturers were such that the valve could be simply removed (both devices are designed to be easy to remove within $24-48 \mathrm{~h}$ of insertion) and discarded if ineffective. In trying to predict patients who will have the greatest benefit, the following points seem likely.

1) There is a greater chance of benefit if there is significant dynamic hyperinflation pre-procedure. Therefore, one strategy could be to perform an incremental exercise test as part of the work up, with measurement of the Borg breathlessness and leg fatigue score [15]. Based on the present authors' data, the procedure would not be offered to a patient whose primary complaint was leg discomfort.

2) The likelihood of reducing dynamic hyperinflation is conceivably diminished if air can enter the target lobe through other channels; this phenomenon is termed collateral ventilation. Two techniques are available for in vivo measurement of collateral ventilation $[16,17]$ and the utility of this variable as a prognostic indicator deserves fuller evaluation.

Given that the technique works in some patients and is relatively safe, it seems inevitable that more patients will be referred for bronchoscopic lung volume reduction in the future and it is likely that advanced physiological techniques will play an increasing role in patient selection.

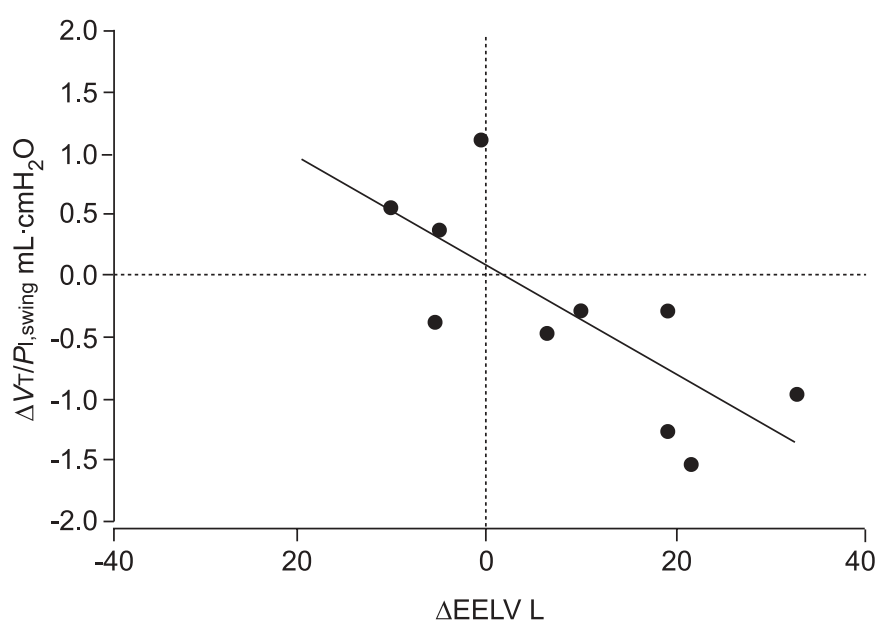

FIGURE 5. Neuromechanical coupling was measured in a subset of patients and expressed as tidal volume $(\mathrm{V} T)$ divided by the amplitude of the inspiratory pressure swing ( $P$ I,swing) during exercise. Improvement at isotime strongly correlated with reduction in dynamic hyperinflation. $\triangle E E L V$ : change in endexpiratory lung volume. Taken from [14].

\section{REFERENCES}

1 Brantigan OC, Mueller E, Kress MB. A surgical approach to pulmonary emphysema. Am Rev Respir Dis 1959; 80: 194-206.

2 Cooper J, Patterson G, Sundaresan R, et al. Results of 150 consecutive bilateral lung volume reduction procedures in patients with severe emphysema. J Thorac Cardiovasc Surg 1996; 112: 1319-1330.

3 Geddes D, Davies M, Koyama H, et al. Effect of lungvolume-reduction surgery in patients with severe emphysema. N Engl J Med 2000; 343: 239-245.

4 Fishman A, Martinez F, Naunheim K, et al. A randomized trial comparing lung-volume-reduction surgery with medical therapy for severe emphysema. N Engl J Med 2003; 348: 2059-2073.

5 Macklem PT. Collateral ventilation. N Engl J Med 1978; 298: 49-50.

6 Lausberg HF, Chino K, Patterson GA, Meyers BF, Toeniskoetter PD, Cooper JD. Bronchial fenestration improves expiratory flow in emphysematous human lungs. Ann Thorac Surg 2003; 75: 393-398.

7 Sabanathan S, Richardson J, Pieri-Davies S. Bronchoscopic lung volume reduction. J Cardiovasc Surg (Torino) 2003; 44: 101-108.

8 Snell G, Holsworth L, Borrill ZL, et al. The potential for bronchoscopic lung volume reduction using bronchial prostheses. Chest 2003; 124: 1073-1080.

9 Yim AP, Hwong TM, Lee TW, et al. Early results of endoscopic lung volume reduction for emphysema. J Thorac Cardiovasc Surg 2004; 127: 1564-1573.

10 Venuta F, de Giacomo T, Rendina EA, et al. Bronchoscopic lung-volume reduction with one-way valves in patients with heterogenous emphysema. Ann Thorac Surg 2005;79: 411-417.

11 Hopkinson NS, Toma TP, Hansell DM, et al. Effect of bronchoscopic lung volume reduction on dynamic hyperinflation and exercise in emphysema. Am J Respir Crit Care Med 2005; 171: 453-460. 
12 Toma TP, Hopkinson N, Hillier J, et al. Unilateral bronchoscopic volume reduction with valve implants in patients with severe emphysema. Lancet 2003; 361: 931-933.

13 O'Donnell DE, Revill SM, Webb KA. Dynamic hyperinflation and exercise intolerance in chronic obstructive pulmonary disease. Am J Respir Crit Care Med 2001; 164: 770-777.

14 Hopkinson NS. Skeletal Muscle Dysfunction in Chronic Obstructive Pulmonary Disease - Therapeutic and Genetic Influences. PhD Thesis. University of London, London, UK, 2005.
15 Man WD, Soliman MG, Gearing J, et al. Symptoms and quadriceps fatigability after walking and cycling in chronic obstructive pulmonary disease. Am J Respir Crit Care Med 2003; 168: 562-567.

16 Morrell NW, Wignall BK, Biggs T, Seed WA. Collateral ventilation and gas exchange in emphysema. Am J Respir Crit Care Med 1994; 150: 635-641.

17 Terry PB, Traystman RJ, Newball HH, Batra G, Menkes HA. Collateral ventilation in man. $N$ Engl J Med 1978; 298: 10-15. 